\title{
Flow Changes after Endovascular Treatment of a Wide-Neck Anterior Communicating Artery Aneurysm by using X-configured Kissing Stents (Cross-Kissing Stents) Technique
}

\author{
Kamil Zeleňák $\cdot$ Jana Zeleňáková $\cdot$ Július DeRiggo $\cdot$ \\ Egon Kurča $\cdot$ Jaroslav Boudný $\cdot$ Hubert Poláček
}

Received: 21 December 2010/Accepted: 14 March 2011/Published online: 31 March 2011

(C) The Author(s) 2011. This article is published with open access at Springerlink.com

\begin{abstract}
Endovascular treatment for a wide-neck anterior communicating artery (AcomA) aneurysm remains technically challenging. Stent-assisted embolization has been proposed as an alternative of treatment of complex aneurysms. The X-configuration double-stent-assisted technique was used to achieve successful coiling of wideneck AcomA aneurysm. Implanted stent can alter intraarterial flow. Follow-up angiograms 4 months later showed flow changes due to used X-technique of stents implantation and filling of the anterior cerebral artery from the opposite internal carotid artery.
\end{abstract}

Keywords X-stent technique - Kissing stent technique Wide-neck aneurysm · Coiling · Flow changes

\section{Introduction}

Anterior communicating artery (AcomA) aneurysm is the most frequent form of aneurysms. Endovascular treatment

\footnotetext{
K. Zeleňák $(\bowtie) \cdot$ H. Poláček

Department of Radiology, University Hospital, Kollárova 2, 03659 Martin, Slovakia

e-mail: zelenak@unm.sk

J. Zeleňáková · E. Kurča

Department of Neurology, University Hospital, Kollárova 2, 03659 Martin, Slovakia

J. DeRiggo

Department of Neurosurgery, University Hospital, Kollárova 2, 03659 Martin, Slovakia

J. Boudný

Department of Radiology, University Hospital Brno, Jihlavská 20, 62500 Brno-Bohunice, Czech Republic
}

for a wide-neck AcomA aneurysm remains technically challenging. Stent-assisted embolization has been proposed as an alternative of treatment of complex aneurysms. The $\mathrm{X}$-configuration double-stent-assisted technique was used to achieve successful coiling of wide-neck AcomA aneurysm. Implanted stent can alter intra-arterial flow. An anterior cerebral artery was filled with contrast from the contralateral internal carotid artery at follow-up angiography 4 months later, which was performed because the patient has a pacemaker and thus could not be performed magnetic resonance angiography.

\section{Case Report}

A 75-year-old woman was treated for incidental wide-neck AcomA aneurysm, which was diagnosed by CTA after syncope and headache. Because of bilateral involving A2 segment of anterior cerebral artery (ACA) into the aneurysm neck and bilateral acute curve of ACA, placement of stent from A1 segment of ACA to ipsilateral A2 segment of ACA was not possible. The X-configuration double-stentassisted technique was used to achieve successful coiling of wide-neck AcomA aneurysm. One week before the procedure, the patient received $75 \mathrm{mg}$ of clopidogrel and $100 \mathrm{mg}$ of acetyl salicylic acid (ASA) daily.

Under general anesthesia, over multipurpose diagnostic catheter (MP; Cordis) and 0.035" guidewire (Storq; Cordis) 6F 80-cm long introducer (IVA; BALT) was placed to right common carotid artery from right transfemoral approach and to the left one from left transfemoral approach. Bolus of 2000 i.u. of heparin was given and patient was heparinized during the procedure (1000 i.u. of heparin per hour). Subsequently $5 \mathrm{~F}$ guiding catheter $(5 \mathrm{~F}$ MPD Envoy; Cordis) was placed into internal carotid via 
the introducer to both sides. Introducers and guiding catheters were flushed with saline only.

Rotation angiography was performed to confirm wideneck AcomA aneurysm with bilateral involving A2 segment of ACA into the aneurysm neck and bilateral acute curve of ACA, by injection of contrast media to right and left internal carotid artery (ICA) (Fig. 1A, B). Ipsilateral ACA was filled dominantly. Under roadmap guidance, a microcatheter (Excelsior SL-10/J; Boston Scientific) with microwire (Sorcerer 009.J; BALT) was placed from right ICA to A2 segment of left ACA after failure catheterization of ipsilateral A2 segment because of acute curve and microcatheter (Excelsior SL-10/45; Boston Scientific) with microwire (Sorcerer 009.J; BALT) was placed from left ICA to A2 segment of right ACA. Microwires were changed to exchange length wire (Synchro-2 angled; Boston Scientific) and microcatheters were removed. Two stents $4.5 \times 30 \mathrm{~mm}$ (Neuroform ${ }^{3}$, Boston Scientific) were then positioned over the microwire. The stents' diameter was oversized, whereas the diameter of A1-A2 was 2.3-2.5 mm. The first stent was deployed in the A2 segment of left ACA-AcomA-A1 segment of right ACA and, second one, in the A2 segment of right ACA-Aco$\mathrm{mA}-\mathrm{A} 1$ segment of left ACA. The microwire (Sorcerer 009.J; BALT) was then used to select the dome of the aneurysm, and the microcatheter (Excelsior SL-10/J; Boston Scientific) catheterized the aneurysm from the left side. The microcatheter (Excelsior SL-10/J; Boston Scientific) was subsequently used to deliver the following coils: GDC $103 \mathrm{D}-7 \mathrm{~mm} \times 15 \mathrm{~cm}$; GDC $103 \mathrm{D}-6 \mathrm{~mm} \times 10 \mathrm{~cm}$; GDC $103 \mathrm{D}-5 \mathrm{~mm} \times 8 \mathrm{~cm}$; GDC $103 \mathrm{D}-4 \mathrm{~mm} \times$ $6 \mathrm{~cm}$; Matrix 2 Helical UltraSoft SR $2.5 \mathrm{~mm} \times 3 \mathrm{~cm}$; Matrix 2 Helical UltraSoft SR $2 \mathrm{~mm} \times 2 \mathrm{~cm}$. A satisfactory

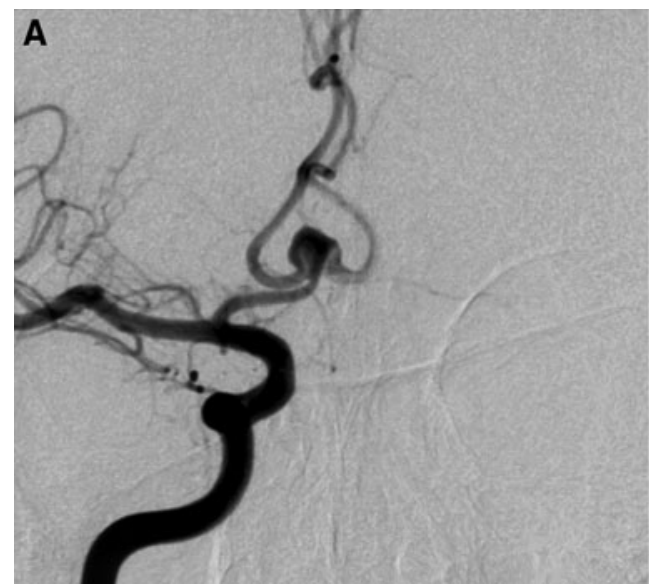

Fig. 1 A Right internal carotid artery angiogram: a wide-neck AcomA aneurysm with bilateral involving A2 segment of anterior cerebral artery into the aneurysm neck and acute curve of right ACA; right anterior cerebral artery is filled dominantly $(6 \mathrm{ml}$ of contrast media injected using $2 \mathrm{ml} / \mathrm{sec}$ flow rate). B Left internal result was obtained (Fig. 2), and patient was neurologically normal on emergence from anesthesia. Hemostasis in the puncture sites was achieved by the closure device (AngioSeal 6 F VIP; St. Jude Medical).

Heparin was not reversed and patient was heparinized for the next $24 \mathrm{~h}$. The patient was given oral clopidogrel $75 \mathrm{mg}$ daily for 3 months and $100 \mathrm{mg}$ ASA daily for life.

Follow-up angiography was performed 4 months later, because the patient has a pacemaker and thus could not be performed magnetic resonance angiography. Angiograms showed flow changes due to used X-technique of stents implantation and filling of the ACA from the opposite internal carotid artery (Fig. 3A, B). This flow changes were not visible immediately after the procedure. The aneurysm neck is occluded with intima (Fig. 3C).

\section{Discussion}

Endovascular treatment of intracranial aneurysms has gained increasing popularity compared with an open craniotomy and intracranial stents are used more frequently. The wide-neck aneurysm might have posed challenges on the traditional endovascular treatment of aneurysm. Y-configuration double stent technique was used for endovascular treatment of wide-neck basilar tip aneurysm [1, $2]$, middle and anterior cerebral artery bifurcation aneurysm $[3,4]$.

The Neuroform stent has applicability in bifurcation aneurysms when inserted partially within the aneurysm fundus and the parent artery. This waffle cone technique reduces the amount of metal deposited in the vessel, thus possibly reducing thrombogenicity and procedure cost [5].

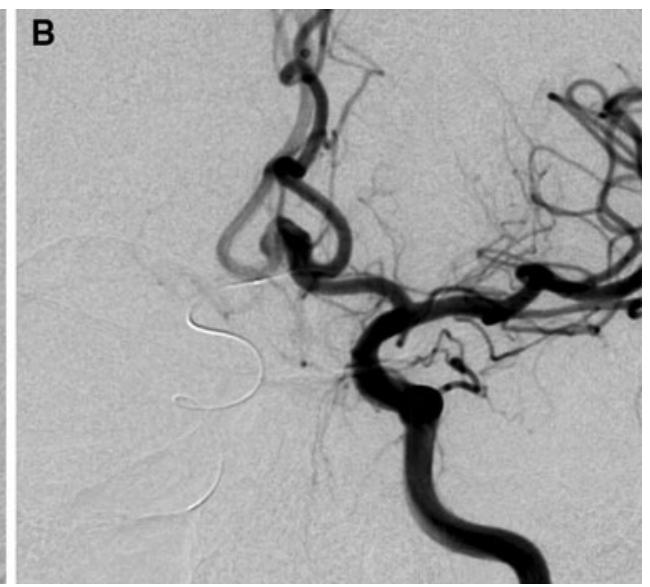

carotid artery angiogram: a wide-neck AcomA aneurysm with bilateral involving A2 segment of anterior cerebral artery into the aneurysm neck and acute curve of left ACA; left anterior cerebral artery is filled dominantly ( $6 \mathrm{ml}$ of contrast media injected using $2 \mathrm{ml} / \mathrm{sec}$ flow rate) 


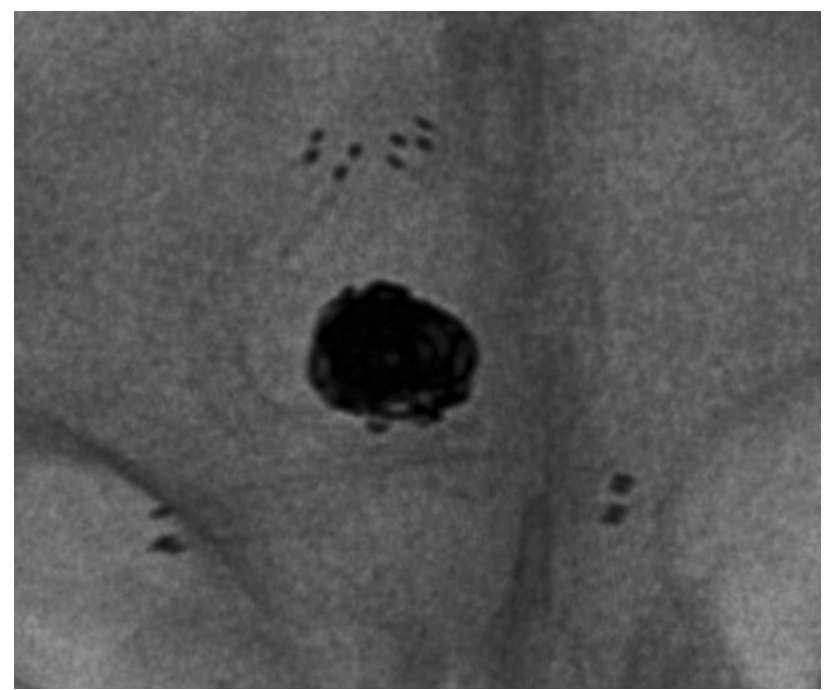

Fig. 2 Two kissing stents and coils in the AcomA aneurysm. The first stent was placed in the A2 segment of left ACA-AcomA-A1 segment of right ACA and second one in the A2 segment of right ACA-AcomA-A1 segment of left ACA

Stent also may be placed across the circle of Willis via the posterior communicating artery or anterior communicating artery [6].

Application of a stent into the parent artery alters the intra-aneurysmal flow pattern that facilitates thrombosis and reduction of coil compaction in the region of inflow zone and prevents subsequent regrowth of aneurysm [7]. Conversely, the Y-stenting might have changed the hemodynamics of the aneurysm blood flow, which might be a contributory factor for rupture [8]. Aneurysm geometry might be one of the key factors responsible for intraaneurysmal flow, which may play a role in aneurysm growth and rupture. Aneurysms with a main axis parallel to the parent artery have a tendency to have a jet flow pattern and uneven distribution of unsteady pressure. These aneurysms may have a higher rate of rupture than those with a main axis perpendicular to the parent artery [9].

Stents are used not only to treat wide-neck aneurysms by the scaffold they provide but also to achieve better initial occlusion rates while sparing the parent artery lumen and to decrease the likelihood of recanalization by the alteration they create in the intra-aneurysmal hemodynamics [10]. Although in our case has not been used a flow diverter, the flow has changed. Anterior cerebral artery filled from the opposite carotid on follow-up angiography. This flow alteration may be associated with higher risk of in-stent thrombosis and ischemic stroke; however, our patient is free of symptoms.

Dual-stent placement technique of X-configured stent placement for the treatment of AcomA aneurysms with wide-neck complex anatomy located on the AcomA and involving both A1-A2 junctions also was used [10], but a second stent was placed by crossing through the struts of the first one and aneurysm sac was coiled through the jailed microcatheter. Only closed cell design stents were used.

In our patient, kissing stents in " $\mathrm{X}$ " configuration (crosskissing stents technique) without putting the second stent through the struts of the first one was used. Microwire was then used to select the dome of the aneurysm and the microcatheter catheterized the aneurysm through the struts of stents.

The Neuroform ${ }^{3}$ stents were selected for this case, because long guidewire provides better stability during stent implantation and open-cell design of the stent conforms better to vascular tortuosity; however, distal outer diameter of delivery system is $2.8 \mathrm{~F}$ and Enterprise or Solitaire stents can be placed through the microcatheter with distal outer diameter 2.3F. The diameter of stents was oversized, because the parent artery restored the original diameter after deployment of oversized stents [11].

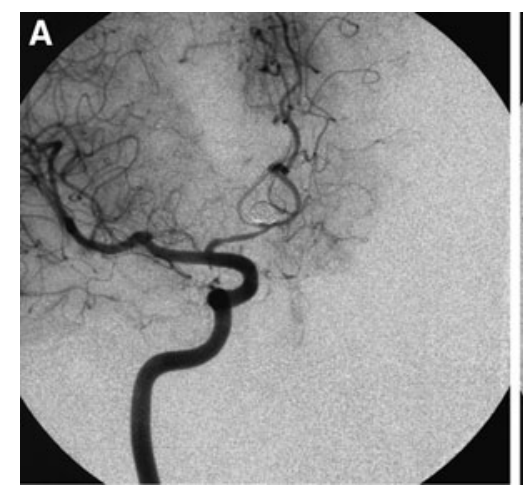

Fig. 3 A Right ICA follow-up angiogram: left anterior cerebral artery is the one mostly filled by contrast through the implanted stent placed in the A2 segment of left ACA-AcomA-A1 segment of right ACA (the same conditions of contrast media injection used as previously). B Left ICA follow-up angiogram: right anterior cerebral artery is filled by contrast through the implanted stent placed in the

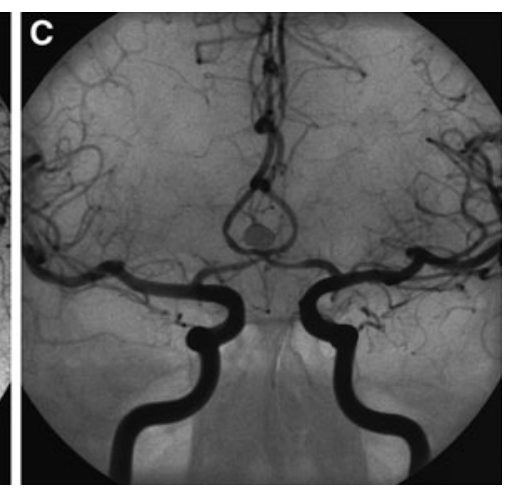

A2 segment of right ACA-AcomA-A1 segment of left ACA (the same conditions of contrast media injection used as previously). C Follow-up angiogram-injection of contrast media to both ICA: no residual perfusion of AcomA aneurysm, the aneurysm neck is occluded with intima; minor intimal hyperplasia in implanted stents 
Delayed in-stent stenosis can occur, but it may be resolved spontaneously [12] and asymptomatic patients do not require additional endovascular treatment or surgical bypass. This may be a phenomenon unique to the application of low radial force, self-expanding stents within the non-atheromatous cerebrovasculature [13].

In our patient, double stenting in " $\mathrm{X}$ " configuration (cross-kissing stents technique) and coiling for wide-neck AcomA aneurysm was used successfully. This is a new technique, which creates a different flow status change.

There was no residual aneurysm perfusion on follow-up angiography 4 months later and flow changes due to used $\mathrm{X}$-technique of stents implantation and filling of the ACA from the opposite internal carotid artery were shown (Fig. 3A, B). Patient has been neurologically intact for 1.5 years after the procedure.

$\mathrm{X}$-configured stent-assisted coiling for selected challenging wide-neck AcomA aneurysm is technically feasible. It needs to be elucidated through longer follow-up.

Conflict of interest The authors declare that they have no conflict of interest.

Open Access This article is distributed under the terms of the Creative Commons Attribution Noncommercial License which permits any noncommercial use, distribution, and reproduction in any medium, provided the original author(s) and source are credited.

\section{References}

1. Chow MM, Woo HH, Masaryk TJ et al (2004) A novel endovascular treatment of a wide-necked basilar apex aneurysm by using a Y-configuration, double-stent technique. AJNR Am J Neuroradiol 25:509-512
2. Thorell WE, Chow MM, Woo HH et al (2005) Y-configured dual intracranial stent-assisted coil embolization for the treatment of wide-necked basilar tip aneurysms. Neurosurgery 56:1035-1040

3. Sani S, Lopes DK (2005) Treatment of a middle cerebral artery bifurcation aneurysm using a double neuroform stent " $Y$ " configuration and coil embolization: technical case report. Neurosurgery 57(1 Suppl):E209

4. Rohde S, Bendszus M, Hartmann M, Hähnel S (2010) Treatment of a wide-necked aneurysm of the anterior cerebral artery using two Enterprise stents in "Y"-configuration stenting technique and coil embolization: a technical note. Neuroradiology 52:231-235

5. Horowitz M, Levy E, Sauvageau E et al. (2006) Intra/extraaneurysmal stent placement for management of complex and wide-necked- bifurcation aneurysms: eight cases using the waffle cone technique. Neurosurgery 58(4 Suppl 2):ONS-258-262

6. Kelly ME, Turner R, Gonugunta V et al (2007) Stent reconstruction of wide-necked aneurysms across the circle of Willis. Neurosurgery 61(5 Suppl 2):249-254

7. Juszkat R, Nowak S, Wieloch M et al (2008) Complete obliteration of a basilar artery aneurysm after insertion of a selfexpandable Leo stent into the basilar artery without coil embolization. Korean J Radiol 9:371-374

8. Yahia AM, Gordon V, Whapham J et al (2008) Complications of Neuroform stent in endovascular treatment of intracranial aneurysms. Neurocrit Care 8:19-30

9. Szikora I, Paal G, Ugron A et al (2008) Impact of aneurysmal geometry on intraaneurysmal flow: a computerized flow simulation study. Neuroradiology 50:411-421

10. Saatci I, Geyik S, Yavuz K, Cekirge S (2010) X-configured stentassisted coiling in the endovascular treatment of complex anterior communicating artery aneurysms: a novel reconstructive technique. AJNR Am J Neuroradiol [Epub ahead of print]

11. Huang Q, Xu Y, Hong B, Zhao R, Zhao W, Liu J (2009) Stentassisted embolization of wide-neck anterior communicating artery aneurysms: review of 21 consecutive cases. AJNR Am J Neuroradiol 30:1502-1506

12. Hasanefendioglu A, Bayrak B, Kocer N et al (2010) Regression of neointimal hyperplasia of an intracranial stent: 6 years followup of a wide-necked aneurysm. Turk Neurosurg 20:90-95

13. Fiorella D, Albuquerque FC, Woo H et al (2006) Neuroform in-stent stenosis: incidence, natural history, and treatment strategies. Neurosurgery 59:34-42 